\title{
Late Pseudo-Exacerbation of Myasthenia Gravis Due to Ectopic Thymoma Invading Lower Cranial Nerves
}

\author{
Gregg MacLean, Alan Guberman and Antonio Giulivi
}

\begin{abstract}
Dysarthria, dysphagia and repeated aspiration in a 54-year-old woman diagnosed and treated for myasthenia gravis 7 years earlier were initially thought to represent a late exacerbation of myasthenia. A cervical mass invading the jugular foramen and causing multiple lower cranial nerve palsies was biopsied and found to represent invasive ectopic thymoma.

RÉSUMÉ: Pseudo-exacerbation tardive d'une myasthénie grave du à un thymome envahissant les nerf crâniens inférieurs Une dysarthrie, une dysphagie et des épisodes répétés d'aspiration trachéo-bronchique chez une femme âgée de 54 ans, diagnostiquée et traitée 7 ans auparavant pour une myasthénie grave ont d'abord été interprétés comme étant une exacerbation tardive de la myasthénie. Une masse cervicale envahissant le trou déchiré postérieur et causant des paralysies un niveau de plusieurs des nerfs crâniens inférieurs a été biopsiée et a été identifiée comme un thymome ectopique envahissant.
\end{abstract}

Can. J. Neurol. Sci. 1990; 17:46-48

An underlying thymoma is found in $10 \%$ of cases with myasthenia gravis. 1 As many as one-third of the thymomas may be locally invasive involving major vessels, pericardium, mediastinal pleura, lungs, lymphatics or distant hematogenous or lymphogenous metastases. ${ }^{2}$ Ectopic thymomas in the neck are extremely rare $^{3}$ and when they do occur are generally located below the level of the hyoid bone.

We present a case of ectopic thymoma in a patient with myasthenia gravis which invaded the base of the skull around the jugular foramen. The resulting lower cranial nerve impairment was initially mistaken for a late exacerbation of the myasthenia.

\section{Case Report}

The patient was 57 years old when she presented in late 1979 with a 1 -year history of progressive fluctuating diplopia, ptosis, dysarthria, dysphagia, generalized weakness and shortness of breath. A strikingly positive Tensilon $($ test and a $20 \%$ to $60 \%$ decremental response to repetitive nerve stimulation at various frequencies confirmed the diagnosis of myasthenia gravis. She was built up to a dose of pyridostigmine $120 \mathrm{mg}$ QID and also started on prednisone, reaching a dose of $100 \mathrm{mg} /$ day. Her weakness, ocular and bulbar signs improved. She developed complications of steroid therapy including hyperglycemia, hypertension, osteoporosis, gastrointestinal bleeding and a compression fracture of T11. Prednisone was tapered to $40 \mathrm{mg}$ on alternate days after 4 months. Chest $x$-ray and mediastinal tomograms were normal. She received a course of plasmapheresis and was admitted for thymectomy by sternal-split procedure in September 1980. Only a small amount of thyroid tissue and some microscopic thymic remnants were removed. She was discharged on prednisone $50 \mathrm{mg}$ and $10 \mathrm{mg}$ on alternate days and pyridostigmine $30 \mathrm{mg}$ QID. Six months later she was able to stop steroids. Two years later, she was treated for an exacerbation of myasthenia gravis with plasmapheresis and then azathioprine $150 \mathrm{mg} /$ day which was stopped after 10 months due to bone marrow suppression.

She remained stable on pyridostigmine $30 \mathrm{mg}$ QID until January 1987 when she began to develop worsening dysphagia, hoarseness, and

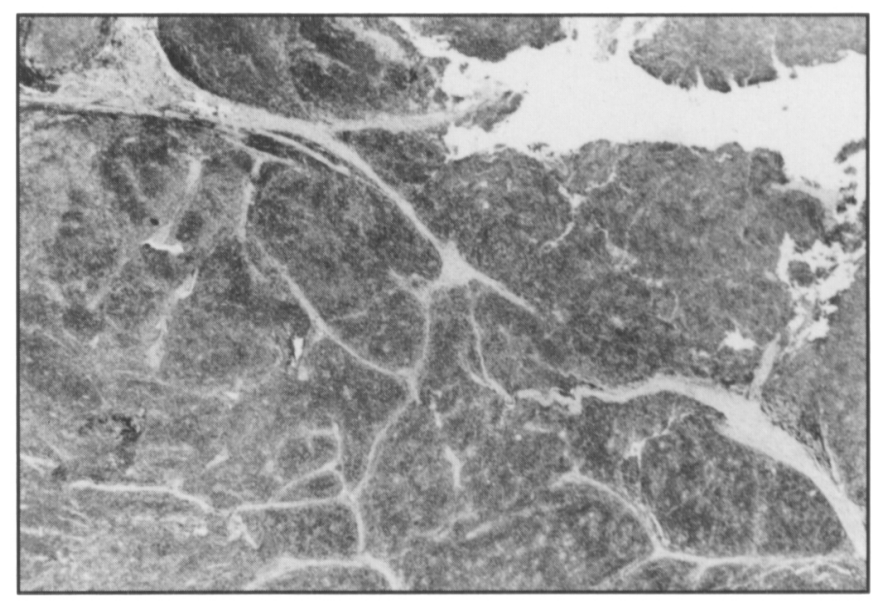

Figure I - Low power view of the thymoma. The tumor is lobulated and separated by thick collagenized connective tissue septae. $(x 100)$

From the Divisions of Neurology and Hematology, University of Ottawa, Ottawa General Hospital, Ottawa

Received May 16, 1989. Accepted in final form October 12, 1989

Reprint requests to: Dr. A. Guberman, Division of Neurology, University of Ottawa, Ottawa General Hospital, Ottawa, Ontario, Canada K IH 8L6 


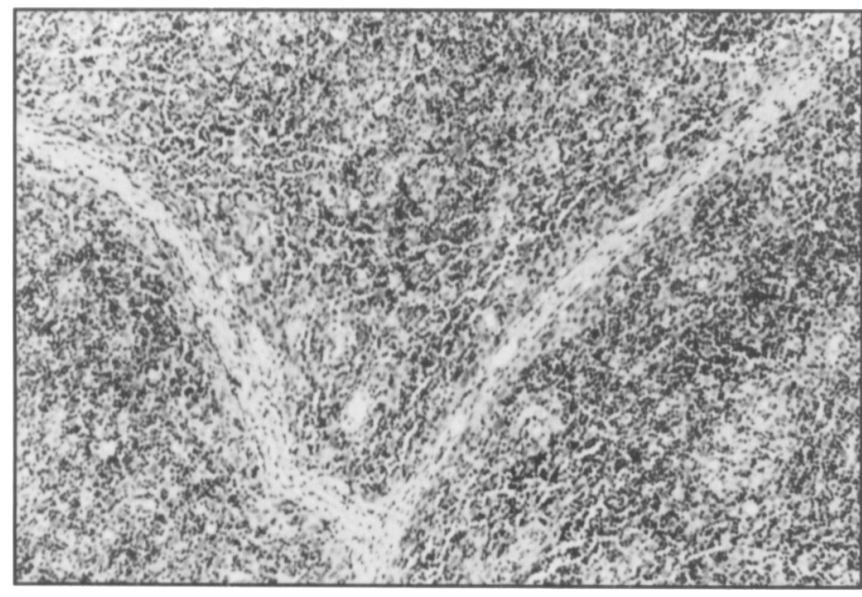

Figure 2 -- Microphotograph showing the bands of collagen compartmentalizing the tumor and scattered epithelial cells some of which are clustered and associated with a moderate lymphocytic infiltrate. $(x / 00)$

recurrent aspiration pneumonia without worsening of ocular symptoms or limb strength. Increased doses of pyridostigmine to $90 \mathrm{mg}$ QID produced no improvement. Acetylcholine receptor binding antibodies were $5.6 \mathrm{nmoles} / \mathrm{Liter}$ a result consistent with myasthenia gravis.

Two months later a right submandibular mass was noticed and initially felt to represent a parotid tumor. Examination revealed normal facial sensation, no ptosis, bilateral mild facial weakness, normal hearing, hoarseness of voice, right palatal weakness with diminished pharyngeal sensation, mild weakness and atrophy of the right sternocleidomastoid and trapezius, striking wasting and fasciculations of the right side of the tongue.

The mass, which extended from the angle of the jaw to below the level of the carotid body was seen to be invading the base of the skull on the right near the jugular foramen on CT scanning. The tumor was debulked and submitted to a panel of 8 pathologists at the Canadian Reference Centre for Cancer Pathology. The tumor histology is shown in Figures 1-3. Epithelial cells were identified on electron microscopy and no malignant features were present. Seven of eight pathologists diagnosed ectopic thymoma and the eighth: "malignant lymphoepithelial lesion". A course of cobalt therapy followed. An MRI revealed residual tumor in the region of the jugular and hypoglossal foramina. The patient was seen one year later and there was no evidence of tumor progression or worsening of her myasthenia.

\section{Discussion}

The thymus gland arises from ventral outgrowth of the third pharyngeal pouches which migrate to the mediastinum. Ectopic thymus tissue may be found anywhere along the path of descent but thymoma arising from undescended cervical thymus is exceedingly rare. In a review of undescended cervical thymomas in 1970, Ridenhour et $\mathrm{al}^{3}$ could find only four previously reported cases in the literature in addition to their own report. We are not aware of other reported cases of clearly invasive ectopic thymoma either with or without myasthenia gravis. While there is no clear agreement on terminology and characterization of thymic histopathology, ${ }_{4}$ the presence or absence of invasion by thymoma has been interpreted as an indication of advancement in clinical stage. In addition to thymoma, other malignant tumors arise from the thymus gland including squamous cell carcinoma, carcinoid, lymphomas, and germ cell tumors. Malignant thymus tumors which are not associated with myasthenia gravis, may present at more advanced stages

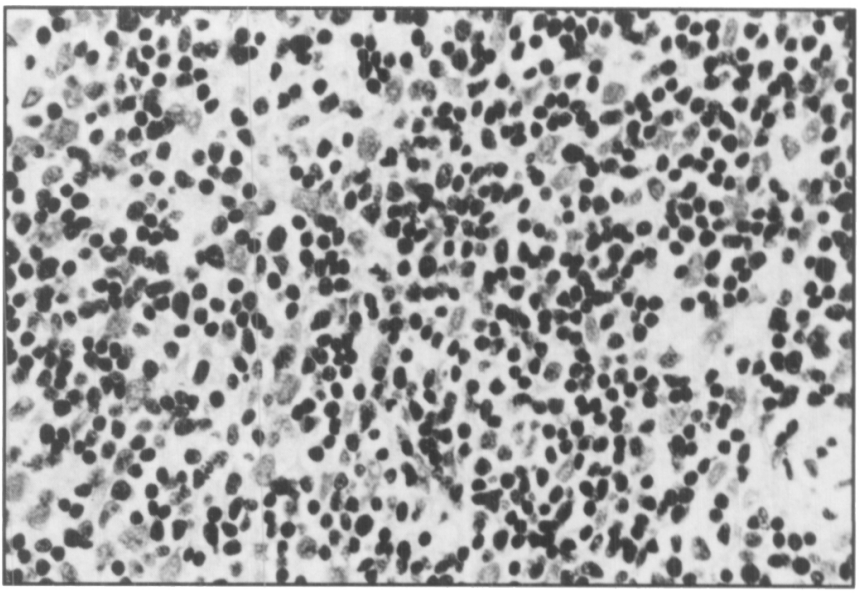

Figure 3-High power view of the thymoma. The lesion is composed of an admixture of epithelial cells and small lymphocytes. (1400)

because of extensive local invasion. ${ }^{5}$ The clinical presentation relates to mass effect and local invasion within the mediastinum and may include dysphagia and cardiorespiratory symptoms. Most thymomas in patients with myasthenia gravis show histological features of predominantly epithelial type and gross tumor invasion is the most important factor determining prognosis. ${ }^{8}$ Treatment of invasive thymoma involves total resection when possible followed by radiotherapy and prednisone ${ }^{1}$ although adjuvant combination chemotherapy has also been effective. ${ }^{7}$ The role of her immunosuppressive therapy with azathioprine four years previously in the development of this unusual tumor is worthy of consideration. There is a 100-fold increased risk of neoplasia developing in renal transplant patients on immunosuppressants, especially central nervous system lymphomas and tumors of epithelial origin. ${ }^{8}$ Azathioprine itself has been implicated in producing an increased risk of malignancy through its immunosuppressant action. ${ }^{9}$ However it is doubtful that this mechanism could be implicated after a fouryear interval and therefore this point is raised only for speculation.

This patient represents a very unusual case of late invasive thymoma leading to cranial nerve dysfunction in a patient with known myasthenia gravis. Late exacerbations occur in myasthenia gravis ${ }^{8}$ and may show features of bulbar and respiratory symptomatology. In this instance, worsening dysphagia and dysarthria could readily be distinguished from an exacerbation of myasthenia gravis on the basis of clinical examination showing unilateral lower cranial nerve dysfunction on the side of the cervical mass.

\section{REFERENCES}

1. Goldman AJ, Herrmann C, Keesey JC, et al. Myasthenia gravis and invasive thymoma: a 20-year experience. Neurology 1975; 25 : 1021-1025.

2. Bernatz PE, Khonsari MA, Harrison EG, et al. Thymoma: factors influencing prognosis. Surg Clin NA 1973; 53: 885-892.

3. Ridenhour CE, Henzel GH, DeWeese MS, et al. Thymoma arising from undescended cervical thymus. Surgery 1970; 67: 614-618.

4. Levine GD, Rosai J. Thymic hyperplasia and neoplasia: a review of current concepts. Human Pathology 1978; 9: 495-514. 
5. Monden Y, Nakahara K, Nanjo S, et al. Invasive thymoma with myasthenia gravis. Cancer 1984; 54: 2513-2518.

6. Verley JM, Holman KH. Thymoma: a comparative study of clinical stages, histological features and survival in 200 cases. Cancer 1985; 53: 1074-1086.

7. Dangaard G, Hansen H, Borth M. Combination chemotherapy for malignant thymoma. Ann Intern Med 1983; 99: 189-190.

8. Bruno A, Adams HP Jr. Neurologic problems in renal transplant recipients. Neurol Clin 1988; 6: 305-325.
9. Katz P, Fauci AS. Immunosuppressives and Immunoadjuvants, Chapter 25. In: Samter M, ed. Immunological Diseases, 4th Ed., Boston, Little, Brown and Company 1988; 1: 675-698.

10. Oosterhuis HJ. Observations of the natural history of myasthenia gravis and the effect of thymectomy. Ann NY Acad Sci 1981; 377: 678-690. 